\title{
Affective atmospheres of sensemaking and learning: workplace meetings as aesthetic and anaesthetic
}

\begin{abstract}
The aim of this paper is to explore sensemaking and learning processes with and through affective atmospheres. We engage with recent research within the 'affective turn' across the social sciences and humanities to conceptualize the significance of quasi-autonomous affective atmospheres that emanate from and also condition collectives of humans and non-humans. Drawing on this atmospheric scholarship, we propose and elaborate an atmospheric analysis of sensemaking and learning processes to examine how such atmospheres aesthetically transform and anaesthetically constrain the potential of bodies, including our own as researchers to affect and be affected to sense and learn. Through empirical engagement with workplace meetings in a UK housebuilding firm, our analysis contributes by explaining how such atmospheres condition sensemaking that both registers the disorganising novelty of events and reduces such ambiguity and equivocality to enable purposeful action. While extant research has suggested how the interplay of these two dimensions of sensemaking enables learning, our analysis contributes by drawing attention to how the production, maintenance and transformation of specific atmospheres in workplace meetings imbues affects that condition these two dimensions of sensemaking. Such atmospheres thus constitute vital, yet seldom discussed, phenomena in conditioning learning within organisational life.
\end{abstract}




\section{Introduction}

In his story of a lost Hungarian army detachment, Weick explains how a map found in a soldier's pocket 'calmed [the soldiers] down' (1990:4) long enough for them to find their bearings - allowing them to learn to make sense of their ambiguous situation differently, coordinating their thoughts and actions to escape - even though the map was of a different area. Despite this early provocation into the role of affect in 'how we learn to make sense and make sense to learn' (Colville, 2016: 4), Weick later lamented his original work on sensemaking was 'basically cool and cognitive' (2010: 545), noting that adding an affective dimension would create a richer interpretation of how meanings of events are enacted in organisations to coordinate learning and action. Responding to such provocations, in recent years the affectivity of sensemaking has increasingly been theorized (Maitlis and Christanson, 2014; Sandberg and Tsoukas, 2015) and empirically explored (Cornelissen et al. 2014; Creed et al. 2014; Cunliffe and Coupland, 2012; Steigenberger, 2015), particularly in relation to learning (Catino and Patriotta; 2013; Heaphy, 2017). However, as this extant scholarship mostly revolves around anthropocentric, and especially psychological, concepts of affect, it arguably circumvents the most intriguing question arising from Weick's (1990) map story: how did the introduction of a non-human body, a map of a different area, precipitate comfort and calm in the soldiers, engendering new potentials for sensemaking and learning?

This unexamined question in Weick's story (1990) provides a starting point for our paper: to empirically elaborate a conceptual approach to explore how relations between humans and nonhumans shape collective affective phenomena that influence sensemaking and learning. Our exploration is informed by the burgeoning 'affective turn' in organisation studies (Gherardi, 2017). Here affect is not conceptualized as human-owned emotion, but as a relational modulation in the agentic potentials of bodies to affect and be affected (Deleuze, 1988: 123) 
with other bodies that are always 'embedded in the material world' (Gherardi, 2017: 355). Such affective bodies are understood heterogeneously to include all organised conglomerations of matter and energy; thus, not just human and non-human animals, but also artefacts, technologies, talk, ideas and technologies (Deleuze, 1988: 127). These treatments of affect thus offer an important challenge to the anthropocentric and logocentric orientation of scholarship on sensemaking (Introna, 2018) and learning (Bell and Vachhani, 2019; Gherardi, 2016; 2017).

Our overarching purpose in this paper is to elaborate the interplay between such agential affects and sensemaking and learning processes. In particular, we explore a less discussed relational affective phenomena - atmospheres. Engaging with scholarship across the social sciences (Anderson, 2009; 2014; Anderson and Ash, 2015; Edensor, 2012; Morris, 2018; Robinson, 2017) and organisation studies (Bell and Vachhani, 2019; Gherardi, 2017; Michels, 2015; Michels and Stayaert, 2017; Julmi, 2017), we understand affective atmospheres (herein 'atmospheres') as relational affects that emanate from encounters between people, spaces, and other bodies but also quasi-autonomously envelop and condition those encounters, spaces and bodies. We argue for atmospheric analyses of sensemaking and learning to elucidate an important, yet notably underexamined, category of relational affects that shapes meaningmaking, sense and causalities (Anderson, 2009; 2014; Anderson and Ash, 2015; Edensor, 2012; Julmi, 2017; Morris, 2018; Robertson, 2017). Our thesis develops across four sections. First, to delineate the potential for engaging with atmospheres, we explain how the relationship between affect, sensemaking and learning has thus far been understood. This review encompasses three strands of scholarship: (i) affect and sensemaking; (ii) affect and learning and (iii) affect, sensemaking and learning. Second, we elaborate our approach to atmospherically analyse sensemaking and learning by conceptualizing atmospheres as distinct affective phenomena, particularly with reference to studies in cultural geography. Third, we outline our methodology for atmospherically researching sensemaking and learning, and the 
empirical context of our study - a housebuilding innovation project in the UK. Fourth, following two meetings within this project, we discuss how interacting aesthetic and anaesthetic atmospheres (Julmi, 2017) respectively transform and constrain sensemaking and learning. Our analysis contributes by generating new insights into the affective conditions through which sensemaking and learning unfolds. By way of conclusion, we further discuss the implications of atmospheric analysis for future studies of affect, sensemaking and learning.

\section{Affect, sensemaking and learning: the potential of atmospheres}

\section{Affect and sensemaking}

Sensemaking scholarship has a longstanding, if relatively under-developed (Maitlis and Christanson, 2014; Sandberg and Tsoukas, 2015), interest in the role of emotions in how sense and actions are co-ordinated and constituted in ambiguous and equivocal situations (Creed et al. 2014; Cunliffe and Coupland, 2012; Steigenberger, 2015; George and Jones, 2001; Weick, 1995; 2010; Weick et al. 2005). Though largely equating affect with human-owned emotion, this research has occasionally gestured toward the constitutive role of more relational, agentic affects within emotionally charged sensemaking processes. Weick (1995: 47), for example, considers how pleasure is generated when a phone line is disconnected while working; this event not only reduces the capacity for a frustrating interruption to work but diminishes the need to make sense of such an ambiguous and equivocal event. Here positive/negative emotions, constituted partly through encounters with non-humans like phones, constitute affective triggers for sensemaking. Weick's (2010) revisiting of his classic analysis of the Bhopal disaster goes further in gesturing towards the sensemaking role of relational affects by exploring those that emanate from, and then quasi-autonomously reshape the agencies of 
humans and non-humans. Evocatively, Weick (2010) opens his paper with an account on the disaster from the French journalists Lapierre and Moro (2001) describing how '[an] atmosphere of extreme depression prevailed for some time over the metal structures of the factory' (Lapierre and Moro, 2001 as cited in Weick, 2010: 537; emphasis added). Although this atmosphere is not theorized by Weick, it does appear an active ingredient in his subsequent analysis of how sensemaking at Bhopal was gripped by a 'mood of pessimism' (Weick, 2010: $545)$ that tragically diminished agential capacities for the plant workers to imaginatively make sense of warning cues before the disaster. Despite this tantalizing glimpse into the dynamics of atmospheres and sensemaking, explorations of affect and sensemaking remain limited to analyses of encounters among human bodies (Cunliffe and Coupland, 2012) or between humans and non-humans (Cornelissen et al. 2014). Engagements with concepts of collective affects, as in atmosphere, that recognize the presence of quasi-autonomous affects on such bodies remain largely lacking.

A rare exception to this atmospheric lacuna in sensemaking scholarship is offered by Introna (2018). Engaging with Heidegger's concept of 'mood' (not atmosphere) to rethink sensemaking in less anthropocentric terms, Introna (2018) explains how moods do not refer to 'a private inner psychological state' (p8), and are not formed within bodily encounters, but rather exist as more diffusive, lingering, affects that shape sense: 'something that befalls us, in some way, or something we already find ourselves in, from the start' (p8). As with the concept of atmospheres (Anderson, 2009; 2014; Julmi, 2017), moods influence immanent bodily senses and actions through differentiated processes of relational 'attunement' (p9) wherein 'certain agentic possibilities appear as relevant and others do not' (p9). Rereading Weick's seminal analysis of the Mann Gulch fire, Introna (2018) explains how the capacities of some bodies to act (e.g. to attempt to outrun the fire or not) interacted with a proximal mood of worry and a distal mood of techno-optimism to generate different actions and sense in the 
firefighters. Introna's (2018) conceptualization of mood emphasizes the rich potential of exploring 'agentic flows [that] are immanent in mundane action, but often transcend such actions as they continually transform the mesh of possible actions' (p9). Yet, some important elements of thought remain to be elaborated concerning how: purposeful, representational, practices (e.g. talk, stories) relate to such diffuse moods; multiple moods interact with each other to condition sensemaking; specific moods (e.g. a boring, exciting mood) shape specific processes of sensemaking. Before explaining the potential of the concept of atmosphere to elaborate such concerns, we will explain how engagements with relationally constituted concepts of affect are equally important to studies of affect and learning.

\section{Affect and learning}

Echoing studies of sensemaking, organisational studies of learning have increasingly developed important insights into the role of affect as integral to learning processes (Brown, 2000; Fineman, 1997; Gherardi, 2016; 2017; Vince, 2011). In recent years this research has also similarly broadened from analyses of affect as human-owned emotion (e.g. Brown, 2000; Fineman, 1997) to theorize affects constituted across the interplay of humans and non-humans (Bell and Vachhani, 2019; Gherardi, 2016; 2017; Vince, 2011). Vince (2011), for instance, explains how by configuring classroom chairs into a lecture theatre style, and then sitting silently on those chairs with his students, he generates confusion that exposes shared audience fantasies for control and unconscious desires for order. This confusing 'spatial psychodynamic' (Vince, 2011) usually ends with a student walking to the front to control the class, instilling power hierarchies, comfort, blame and passive learning. Although offering a useful study to reflect on the material and affective conditions that might accompany passive learning, Vince's 
(2011) analysis figures non-humans, as in specific classroom configurations, in unhelpfully essentialist and deterministic terms. Consequently, it is not clear why these students were affected to learn by these chairs in this way and how deviations emerged. After all, can we confidently assume such a classroom configuration will always imbue such affects? With Gherardi $(2016 ; 2017)$ we propose to extend more profoundly the relationality of affect to nonhumans in order to help address such complexities. Gherardi (2016) offers the account of Sara, an art restorer, to elucidate a more relational, immanent, composition of affect and learning: 'between Sara's hands on the canvas, her feeling of what can/should be done, the tools and the materials at hand to accomplishing the single task in restoring, the knowing in the situation of what to do, and the non-knowing coming from gut feelings' (p693; see also Bell and Vachhani, 2019: 10-15). Here the affectivities of learning are not constituted by non-humans or humans (as in Vince, 2011) but emerge more relationally within dynamic modulations in bodily capacities 'to be affected and affect' (Gherardi, 2017: 355). Significantly, this strand of organisational scholarship has also started to recognize how affective atmospheres might shape learning (e.g. Bell and Vachhani, 2019; Gherardi, 2017). Yet, there remains a lack of granularity in explaining how: atmospheres might interact with each other, and such bodily affects, to shape learning; representational and purposeful practices (e.g. sensemaking) shape such atmospheres; specific atmospheres (e.g. boring, exciting) might condition specific modes of learning (e.g. exploitative/exploratory - March, 1991). Although these lacunas overlap noticeably with those in Introna (2018), our argument here is not that studies of sensemaking and learning can separately benefit from atmospheric analysis but, rather, that such analysis offers an opportunity to deepen theorizations of the affective dynamics connecting sensemaking and learning. By discussing recent studies of affect, sensemaking and learning we can elaborate this opportunity. 


\section{Affect, sensemaking and learning}

Thus far only a handful of studies have explored the affective dynamics between sensemaking and learning (e.g. Catino and Patriotta; 2013; Heaphy, 2017; Ucbasaran et al. 2013). Although decidedly anthropocentric, such work remains instructive for our purposes here. This is because, unlike Introna (2018) and Gherardi (2017), such research explains how specific affective phenomena influence specific sensemaking and learning processes. For example, intensely positive and negative emotions (e.g. overconfidence/fear) are strongly linked to a decline in cognitive capacities to register, and thus organise, equivocal and ambiguous events into an emergent order to enable learning (Catino and Patriotta, 2013; Heaphy, 2017; Ucbasaran et al. 2013). Such studies also suggest how affects interplay with representational and purposeful processes. For instance, in their field study of learning from errors in the Italian Air Force, Catino and Patriotta (2013: 457) explain how pilots retell each other 'chilling' stories of past flight mishaps to cultivate emotional intensities to trigger sensemaking and internalize learning. We suggest that any atmospheric analysis of sensemaking and learning would similarly benefit from developing an equivalent level of granularity in how specific affects interplay with specific (and representational and purposeful) processes of sensemaking and learning. To develop such a granular analysis, it is necessary to first theorize more fully the relationship between sensemaking and learning.

As introduced at the head of this paper, Colville et al. (2016) neatly summarize the sensemaking and learning nexus as 'how we learn to make sense and make sense to learn' (p. 4); thus suggesting two dimensions of sensemaking constitute learning. The first, what we understand here as 'making sense to learn', is a conceptual, highly instrumental, ordering practice of extracting meaning from the flow of equivocal and ambiguous events often with reference to accumulated experiences - an asking of 'what is going on' and 'what to do next' (Weick et al. 
2005: 410). The second dimension, identified as 'how we learn to make sense', is perceptual, and less instrumental: here actors' act and sense 'how the sensing of events is accomplished' (Colville et al. 2016: 9). This dimension of sensemaking is disordering, opening up new, indefinite, potentials to make sense differently. Learning is thus to be conceived as a tension, perhaps balance (Guiette and Vandembempt, 2016), between these two dimensions of sensemaking - between organisation/disorganisation (Clegg et al. 2005). This is because equivocal and ambiguous events cannot be registered, let alone ordered by accumulated experiences, if sensemakers cannot imagine and explore future equivocal and ambiguous, disorganising, potentials of making sense differently (Colville et al. 2016: 8). That is to say, as when finding the wrong map helps in the escape from a Hungarian forest (Weick, 1990), 'in order to map unknown terrain, to create new places, to defer our perception, we need fantasy, imagination and randonnée - a journey with no fixed route' (Clegg et al. 2005: 156; original emphasis).

Three imperatives for atmospheric analysis of sensemaking and learning

Drawing together our argument thus far, following Introna (2018) and Gherardi (2017), we contend that the interplay of human and non-human bodies conditions relational, collective affects that immanently and quasi-autonomously condition the agential capacities of human bodies to sense and learn. Moreover, such affectively charged capacities constitute sense immanently with, and beyond, the flow of mundane actions (Introna, 2018; Sandberg and Tsoukas, 2015) rather than only within interruptions to activities (Weick, 1995). With Gherardi (2017) and others (Anderson, 2009; 2014; Bell and Vachhani, 2019; Julmi, 2017), we conceptualize such affects as atmospheres. But going beyond this general argument, pace 
Colville et al. (2016), we propose a more granular conceptualization of the role of atmospheres in sensemaking and learning. Specifically, we want to argue that atmospheres help mediate how human sensemakers sustain tensions between the disordering practice of 'learning to make sense' and the ordering practice of 'making sense to learn'. Thus, we propose that atmospheric analyses of sensemaking and learning can contribute in helping understand the "more-thanhuman' and 'more-than-representational' (Gherardi, 2017; Introna, 2018) affective conditions, through which tensions between these two sensemaking practices are sustained, to enable learning. Inspired by existing anthropocentric research on affect, sensemaking and learning, we further suggest such affective conditions are far from amorphous and autonomic. Rather, atmospheres possess specific intensities, rhythms, qualities and forces and they interact with each other and other affects, including other atmospheres, in specific ways (Anderson and Ash, 2015). What is more, they are also partly constituted by, rather than simply excessive to, practices, including sensemaking, that are more or less representational and purposeful (Anderson, 2014; Degen et al. 2017; Edensor, 2012; Sage et al. 2019). Summarizing, we propose three imperatives for atmospheric analyses of sensemaking and learning: (i) to register quasi-autonomous relational affects that condition transformative and constraining capacities for sensemaking; (ii) to dissect the multiple, specific affects that constitute such atmospheres and how they participate in the dis/ordering of equivocality and ambiguity to enable learning and (iii) to explain how those affectivities interplay with representational and purposeful practices of sensemaking and learning. Before exploring how these imperatives can be pursued through atmospheric analysis, it is first vital to conceptualize atmosphere as an analytically distinct affective phenomenon.

\section{Conceptualizing atmospheres, sensemaking and learning}


Conceptualizing relational affects, like atmospheres, is an innately challenging task. This is because such affects resist representation wherein knowing subjects articulate knowable objects (Anderson, 2009; 2014; Julmi, 2017). In other words, relationally constituted affects resist the anthropocentrism and logocentrism of (most) approaches to sensemaking (Introna, 2018) and learning (Gherardi, 2017). Regarding atmospheres, the challenge of thinking their relationality is readily exampled in everyday life where perhaps we cannot predictably experience an 'exciting' work atmosphere by the presence of specific material stimuli - for example, bright, multi-coloured, office décor (Julmi, 2017: 8) - or through the contagion of intersubjective accounts of such 'excitement' as that atmosphere is partly materially mediated. In other words, atmospheres, are irreducible to either subjective or objective elements as they are constituted in dynamic, unfolding, relations between subject/object (Anderson, 2009; 2014; Julmi, 2017). Additionally, atmospheres, are not conceived as modulations in actually observed agencies of bodies but their potential capacities to act (Anderson, 2009; 2014). In his reading of Spinoza's affective philosophy, Deleuze usefully links the relationality and potentiality of affect by explaining affects as relationally constituted modulations in the positive (joyful) or negative (sad) agentic potential of bodies (Deleuze, 1988: 127) to be affected by and to affect other bodies, human and non-human (Deleuze, 1988; 1992). To be clear, here joy and sadness are not synonymous with respective emotional states of happiness and despair but rather relationally constituted increases or decreases in human capacities for action. Indeed, joyful affect cannot be fully synonymous with happiness because 'it is by nature open to adventure, and adventures always involve hardship. Joy in adventure cannot be had without affirming the hardship' (Massumi, 2015: 209). We must also recognize that atmospheres uniquely differ from other relationally constituted affects. This is because they are said not to be equal to the sum total of fleeting bodily affects, such as joy or sadness, constituted in the 'imbrication between elements [as in tangible or ideational bodies]' within encounters 
but rather equate to the 'collective forms of affective capacities' that emerge as quasiautonomous, diffusive, lingering, phenomena from those bodily affects, and then envelop and sometimes condition them (Lancione, 2017: 1017). The quasi-autonomous status of atmospheres implies they possess an ambiguous causality such that 'an atmosphere is at once an effect that emanates from a gathering, and a cause that may itself have some degree of agency' (Anderson, 2014: 156; emphasis added).

Although atmospheres are only starting to be discussed in organisation studies (Bell and Vachhani, 2019; Gherardi, 2017; Julmi, 2017; Michels, 2015; Michels and Steyaert, 2017), there are longstanding, if embryonic, suggestions as to how they shape sense(making) and learning, particularly within cultural geography. Anderson (2009), for example, insists that atmospheres 'are resources that become elements within sense experience' (p79). Similarly, several cultural geography studies have explored how atmospheres shape bodily capacities for learning across diverse sites, including museums (Morris, 2018), public art (Edensor, 2012; Michels, 2015) and universities (Robinson, 2017). Such atmospheric scholarship is useful in supporting the translation of our three above imperatives into a triadic conceptual framework for atmospheric analysis of sensemaking and learning.

The first imperative to draw into our conceptual framework is to explain how specific atmsopheric affects might condition different sensemaking practices. Following Colville et al. (2016) these different dimensions of sensemaking can be conceptualized in terms of disorganising, perceptual practices of learning to make sense and organising, conceptual practices of making sense to learn. The atmospheric affects that might sustain these two practices can be usefully conceptualized with reference to Julmi's (2017) distinction between aesthetic and anaesthetic atmospheres: 'aesthetic atmospheres go beyond and break with the perceiver's expectations, turning [their] attention to the unique, unforeseen aspects of the 
environment. Anaesthetic atmospheres confirm and align with the perceiver's expectations ... anaesthetizing the experience' (Julmi, 2017: 13). Although Julmi's (2017) distinction broadly resembles Deleuze's (1988) distinction between joyful/sad affects that augment/diminish capacities to affect and be affected, Julmi (2017)'s is more useful for our approach here insofar as it explicitly focuses attention on registering atmospheric modulations in perceptual capacities for bodies to register and sense the new. Although not employing these concepts, Michels' (2015: 260) brief account of his atmospheric attunement to an open-air artistic performance helps elucidate such processes. In his account he describes how at first an (anaesthetic) atmosphere of unpleasantness assembled as he watched the performance in a rainy and windy night. Thus, he became unable to distinguish the event from the weather or the (sad) affect of the weather diminishing the capacities of heterogeneous bodies. Accordingly, in the moment, he made sense of the performance as frustrating, confusing and unpleasant. Yet, when he moved inside a nearby truck and warmed up, he noticed the beautiful (aesthetic), vaporous, interplay of the light with the rain. As he generated new sense from the performance, his actions, feelings and thoughts can be said to have been conditioned by the transformative, an/aesthetic force of atmospheres (Michels, 2015).

Our second conceptual imperative involves dissecting the multiple, specific affects and associated transformations that constitute atmospheres and how they participate in the dis/ordering of equivocality and ambiguity - enabling learning (e.g. Michels (2015) learning about atmospheres above). Anderson and Ash (2015) explain specific atmospheric interactions and transformations with the Deleuzian concept of 'threshold' (Deleuze, 1988: 124). Such transformations are said to occur as the configuration of bodies from which an atmosphere emanates changes beyond a certain threshold such that the atmosphere, and the 'global' affect it was generating, will reduce; this threshold marks the moment where this affect ceases, whereby a new atmosphere is generated, or a previously marginalized atmosphere can grip 
those bodies. Individual bodily capacities are said to either resonate with one atmosphere or another, or else are transforming from one modulation to another (as in Michels, 2015). Thus, we suggest, through our reading of Anderson and Ash (2015), that atmospheres cannot enable individual bodies to hold the ordering/disordering dimensions of sensemaking in balance as bodies are either attuned to one atmosphere and its affect or not (within certain thresholds). Yet, such atmospheric interactions and transformations do generate different capacities for bodies, such as Michels (2015), within a collective to order/disorder the equivocality and ambiguity of events (Colville et al., 2016); thus, to respectively 'make sense to learn' and 'learn to make sense'.

Our final conceptual imperative encompasses how atmospheres connect with specific representational and purposeful practices. An increasing number of scholars have explained how atmospheres interplay with articulated meanings and purposeful actions, alongside less articulable and purposeful elements (e.g. Anderson and Ash, 2015; Bell and Vachhani, 2019; Degen et al. 2017; Michels and Steyaert, 2017). Edensor's (2012) ethnography of annual visits to the Illuminations in the seaside resort of Blackpool on the coast of North West England is particularly helpful in thinking such interactions. Edensor (2012) explains how the combination of representational symbols (e.g. illuminations with recognizable celebrities, national imagery, folk tales) and more 'nonrepresentational' elements (e.g. brightness, colour, weather, walking tempos, music) within and around the Illuminations instil collective recognition in many visitors of an exciting, happy, festive, and cheerful atmosphere (Edensor, 2012: 1108). Significantly, this atmosphere is said to only take shape because it is instrumentally anticipated, articulated, felt, and reinforced each year; thus, inspiring the purpose of future visits. Thus, while Introna (2018) posits affect (as in 'mood') as 'the unsaid of sensemaking' (Introna, 2018: 14) and Gherardi reads affect as that 'beyond the threshold of awareness, subjective meaning and discourse' (p348), we instead follow Edensor's (2012) understanding that the 'active 
coproduction of an affective milieu is certainly not suspended in mute attunement' (p1119). When related to an atmospheric analysis of sensemaking and learning, this proposition also suggests that the representational outcomes of sensemaking (e.g. plausible accounts and explanations - Maitlis and Christanson, 2014), as well as the purposeful talk involved in ordering ambiguous and equivocal accounts, including the naming of atmospheres (as in Weick, 2010), are textual bodies of meaning that directly condition, and are conditioned, by the emergence of specific atmospheres (Anderson and Ash, 2015).

Our triadic conceptual framework orientates us to explore three questions with our empirical case. First, how do anaesthetic and aesthetic atmospheres enable actors to make sense to learn and learn to make sense? Second, how are such atmospheres held in tension to enable learning? Third, how do human representational and purposeful sensemaking and learning practices condition these atmospheres, and how are they in return conditioned by them? Before introducing our empirical material to explore these questions, we will first discuss our methodology and research context.

\section{Methodology and research context}

We first started to atmospherically engage with sensemaking and learning within a government funded research project concerning innovation in UK housebuilding. Within this project the first and second authors of this paper observed six design meetings in a construction firm, BuildCo, in the English Midlands. We did not set out to gather this dataset to explore atmospheres, instead we became attuned to their vaporous presence as we were 'following the actors [and] that which makes them act' (Latour, 2005: 237). In our case the actors were these design meetings. Access to these meetings was authorised by the Product Director who had 
arranged the meetings to develop a series of new standard house type designs using a new computer-based 3D design system - Building Information Modelling (BIM). The six meetings were part of an innovation project that combined learning about a novel design and building process (BIM) with the production of standard house types to improve performance predictability for customers. The original, and explicitly stated, aim of this innovation project was to ensure three building systems (brick and block, timber frame, steel frame) were dimensionally aligned around a standard house type envelope to provide clients with fixed construction costs and timeframes for different housing products. BuildCo invited us to attend these meetings to explain how such innovations can be developed with the hope of improving similar projects. All meetings were attended by BuildCo design engineers and key suppliers (i.e. for roof trusses, steel frames, timber frames). Meetings were recorded in field notes and four meetings were, once all the participants consented, also audio video recorded. We also interviewed five key participants in the meetings to reflect on their experiences and had access to the evolving design models in BIM and other documentation (e.g. meeting agendas and minutes, planning documents, relevant policy guidance). Over a four-month period we collected over 15 hours of audio and video recordings, 25 pages of field notes and over 250 files of project documentation.

We became attuned to the presence of quasi-autonomous atmospheres across these meetings when, in the sixth and final meeting at BuildCo, we experienced a shift from what we now, with Julmi (2017), term an anaesthetic to aesthetic atmosphere. This shift was joyful, not in the psychological sense of imbuing a state of happiness, indeed it was somewhat uncomfortable to experience, rather it was joyful in the Deleuzian sense that it increased the capacities of bodies to affect and be affected (Deleuze, 1988; 1992). This moment constituted the most palpable atmospheric transformation during our study, wherein we experienced a transformation in the potentials of bodies to act that rapidly enveloped and transformed bodies in the room. We 
conceive this affective shift as atmospheric insofar as our attunement to it, and its sensemaking and learning affects, survived, within certain thresholds (Anderson and Ash, 2015), the absence of bodily encounters from which it was generated. Indeed, this atmospheric shift may continue to shape our sensemaking and learning. Within this atmospheric transformation our own potentials as analysts to act, to sense, to learn, were also augmented. Specifically, we were prompted to follow, across our empirical materials (video recordings, field notes, emails), an accumulated anaesthetic constraint on potentials for bodies to act. We can understand this affectively charged moment as an analytical 'hot spot' (p172), to use MacLure's (2013a) term - a 'productive disconcertion ... [that can] ... undermine the analyst's self-assurance' (p172). In what follows we present two ethnographic vignettes of these transformative events. These two vignettes are affectively written to capture how humans and non-humans modulated together with collective rhythms, qualities, forces and intensities that were conditioned by and conditioned future potentials for bodies, including our own, to act (Bell and Vachhani, 2019; Gherardi, 2018). We intend these vignettes to attune the reader to contrasting aesthetic and anaesthetic atmospheres (Julmi, 2017) and the conditions through which thresholds emerged, transforming those atmospheres. Attunement is mobilized here as methodological technique wherein the author seeks to locate the reader in the 'qualities, rhythms, forces, relations and movement' of bodily potentials that constitute 'atmospheric attunements' (Stewart, 2011: 445). These two vignettes were constructed from the recollections of the researchers involved, fieldnotes, and video recordings of each event. We did not employ coding to develop or analyse our two atmospheric vignettes. Our reasoning being that the 'unavoidably linguistic nature of coding - its trade in signs - ignores the entanglements of language and matter, words and things. Materiality is endlessly deferred in a relay of signs' (MacLure, 2013a: 171). In other words, coding struggles to apprehend both the relationality and potentiality of affect (Bell and Vachhani, 2019; Gherardi, 2017; MacLure, 2013a). 
Instead of coding, our strategy for analysing our case consists of an affective form of analysis that is informed by wider developments in 'post-qualitative research' (MacLure, 2013b). The prefix 'post' is deployed here to draw attention to a departure from qualitative research premised upon coding and its humanistic logic of representation. As MacLure (2013b) explains, qualitative research usually assumes data is an 'inert and indifferent mass' (p660) waiting to be interpreted by an autonomous coder. Post-qualitative research instead emphasises how 'data have their ways of making themselves intelligible to us. This can be seen, or rather felt, on occasions when one becomes especially 'interested' in a piece of data' (MacLure, 2013b: 660; emphasis added). Affective analysis is thus integral to post-qualitative research encompassing embodied techniques that amplify affective intensities, such as the surprise felt in the sixth meeting, to figure 'out what the research can "do," what it can become, and how it can continue to affect and transform' (Ringrose and Renold, 2014: 778), enabling learning and new sense (MacLure, 2013b). Our own affective analysis consisted of two practices. First, we, discussed in meetings and emails how this surprising event unfolded and then what these events could do for various concepts including: sensemaking, learning and relational affect. As we drew these specific concepts into dialogue with this surprising affect, we were augmented with a (joyful) potential for (re)thinking sensemaking and learning. This might also be called a 'gut feeling' (Gherardi, 2017: 693) that 'point to the existence of embodied connections with other people, things and thoughts, that are far more complex than the static connections of coding' (MacLure, 2013a: 172). Second, we then started to write, including within earlier versions of this paper, about what such events can do for concepts of relational affect, sensemaking and learning, Affective writing was thus a crucial step in the ongoing affective experimentation that attuned us to the transformative potential of the events we followed (Gherardi, 2018; Ringrose and Renold, 2014). 
We propose the term 'atmospheric analysis' to describe scholarly learning that explicitly registers the qualities, forces, intensities and rhythms of atmospheric transformations as an integral part of the analytical process. Our orientation to this atmospheric form of analysis also guided the sequencing of our vignettes in this paper. That is, as we affectively experienced, discussed, wrote and thought with the shift in atmosphere in the sixth meeting, we reflected differently on the previous meeting. We suggest it was this atmospheric shift that allowed us, and the practitioners involved, to make sense differently, of past events, but also sensemaking and learning more widely. In other words, we learned to make sense differently of how we had previously made sense to learn (Colville et al. 2016). To remain open-ended to what such affective intensities might (still yet) do, we present our two vignettes here in a nonchronological sequence. Our reason for doing so is to invite readers to experience, as we did, not just this atmospheric transformation but how it enabled our own learning, as well as the learning of the participants in our study. The broader point here is that 'analysis never stops; it is always ongoing in ways that flow through and inside of research projects intra-acting and shaping future research encounters as part of the complexity of the research assemblage' (Ringrose and Renold, 2014: 778). And it is because of the (ongoing) vitality of such relational affective phenomena that we frame our approach not as an analysis of the distinct role of atmospheres in shaping sensemaking and learning, but as an atmospheric analysis of sensemaking and learning.

\section{Atmospheres of sensemaking and learning}

$22^{\text {nd }}$ June: the clash detection workshop 
We are back in the same meeting room. It is another partly sunny but cool summer morning in the English Midlands. The room is functional but unremarkable - bland and devoid of decoration, except a single wall mounted company logo. The white painted walls are poorly lit by fluorescent lighting installed within generic white suspended ceiling tiles. A row of partially opened south facing windows allows some broken natural light into the room through partly damaged vertical blinds that occasionally clatter in the light breeze. Seven participants are seated, almost motionless, in black, worn, office chairs around three long light wood veneer meeting tables, assembled into a long rectangle with a screen at one end. [Author 1] was told to arrive thirty minutes after the meeting started: no-one reacts to her presence as she arrives and unpacks her field notebook from her backpack. A few familiar noises compose the room: the drone of the projector fan, the occasional passing vehicle on the access road outside, and the unfolding of another technical conversation. This time a designer from the timber supplier is demonstrating how to use the clash detection software to the others who appear less experienced in its use. It is later evident that this tutorial is intended to prepare the participants to undertake the building component clash detection exercise on the standard designs they have spent months developing. But, as the researcher arrives, there is no introduction as to the purpose of the ongoing activity. The other participants follow this tutorial, making occasional notes, or asking technical questions (e.g. 'can you set that magnitude [the tolerance for registering a clash]?') as various windows containing building designs and settings are opened and closed on the projector screen.

After about 45 minutes a participant casually asks if the main structural designs (the internal timber frame, the roof trusses, and the brick and blockwork) can be integrated to identify any clashes between their components. The participants verbally 
acknowledge this shift in activity, as the software is re-configured from offering a tutorial to evaluating their own work. One of the participants jokes: 'No pressure, right' and the room resounds with polite laughter. The architect responds: 'Oh I know they don't fit, don't worry' as one participant ironically ripostes, 'So why haven't you notified us [using the notification system that was demonstrated in the tutorial]'. Despite these light-hearted caveats, when the 3D design model appears [Figure 1] the participants stare suspensefully for a few seconds at the screen. The silence is startling. A supplier punctures the air first: 'that's not what happened yesterday', the demonstrator then starts to discuss co-ordination points but is interrupted by the architect: 'That's quite strange. I'm not surprised by the timber frame, because we knew that it didn't come in right last time, but the trusses did come in the right place'. Her furrowed eyebrows and her modulating vocal tone and volume indicate surprise and confusion. The ensuing discussion is entirely devoid of humour as the participants attempt to make sense of what they are viewing on the screen. The project manager is clearly frustrated as he acerbically remarks of the software: 'So it doesn't really help, does it? Because I thought the whole point of Glue [BIM clash detection software produced by Autodesk] was to show the problems, but it makes it even worse because [it was all] coordinated, [now] it's not in Glue'. This provokes a direct challenge as one participant pushes back against the project manager by explaining how: 'You're missing the point though, Glue is showing the problem. There is a coordinate problem'.

\section{[Insert Figure 1.0]}

As the conversation continues, the relatively unvarying vocal tones and volumes, and structured conversational turn taking, that composed all the earlier meetings, have been displaced. The room feels uneasy, uncertain, tense. The talk, and the actions to take, 
become difficult to predict as the participants interject, interrupt and talk over each other. This was not on the agenda. For a couple of minutes, the project manager remains unusually silent as others seek to explain what can be done; he then interrupts in frustration: 'The whole point today was to make sure it all ties together. That was the whole point of today. We were to do a clash and find out where the bits don't work!'. As the project manager exclaims at the lack of progress, one participant challenges him: 'I think what we were trying to do, the purpose of today was, primarily, to understand what Glue can do'. Exasperated, the project manager retorts: 'that's not what we discussed - we said at the last meeting, we would do the clash and following what Glue highlighted, we'd finalise the models. Well, we can't finalise the models because the models don't even line up today!'. The timber frame designer then asks the room what starting, or 'datum', co-ordinates the suppliers were using to build their design models. It becomes apparent that in earlier meetings a common set of starting co-ordinates were not used; instead cosmetic workarounds were employed by the architect to make it appear as though the models were aligned to keep the meetings on track. The architect defends herself by explaining how her workaround was visible to all participants in earlier meetings - yet somehow the message was missed. After the end of the meeting [Author 1] leaves the meeting feeling energised and quickly emails [Author 2 and 3]: 'The meeting I went to this morning (clash detection workshop) was incredibly interesting for us ... they were trying to use a new software to do clash detection, which revealed that their designs actually had all different coordinates all along! (which they didn't see before). This turned into a bit of a controversy, [BuildCo] being frustrated that they couldn't get what they wanted out of this meeting, one week before the final deadline!'. 
It is the fifth and final progress meeting. Eight participants are seated around the table. The project manager rhythmically reads actions from the previous meeting, inviting each supplier to confirm completion, and then physically ticking them off their actions. Technical statements and questions from the project management unfold slowly, purposefully, with limitation modulation in vocal tone and volume, and are received by the participants with subdued head nodding or confirmatory silence. But the meeting is far from austere - the participants often puncture their dry, technical, exchanges with smiles and jokes. When the BuildCO BIM manager asks, 'who has used Glue? [the clash detection software]', the architect replies 'No - only on ethics!' - making a pun about solvent abuse. A few minutes later after the project manager asks if one supplier has their designs available, he receives a nod, and then proclaims to the room 'we're all pretty much there apart from today's discussions on finishing it. Then in next couple of weeks, if we can have that little clash exercise'. As he affirms progress, he looks around at the steel frame supplier who gently nods in agreement. After his gaze moves elsewhere, the architect knowingly smiles at the steel frame supplier, hinting at a backstory of doubt, but the interaction is unseen by the project manager. The project manager then checks with the architect if she is 'happy' with the planned clash workshop [for later in the month], she responds: 'obviously if it throws out loads of clashes, if we need to aim for the end of the month, we still need to be able to have a bit of time to sort those out'. The suppliers continue to update BuildCo on progress, the architect, unprompted, loads up two design models into Revit [BIM design software produced by Autodesk]: 
The first design to appear on the screen is the 3D brick and block model, produced by the architect. The conversation at this point concerns whether the timber frame supplier has a model sufficiently developed to enable the planned clash detection workshop. As the supplier explains their progress to the BuildCo BIM manager, the project manager interrupts to declare: 'I think we've probably got enough already there to have a play [in the clash detection software]'. During the unfolding conversation the architect adds the timber frame model of the lower floor of the house - it immediately misaligns with the brick and block model (Figure 2). Revit indicates this misalignment with yellow highlight. Three participants in the meeting, including the timber frame supplier, the BuildCo BIM manager and the architect's senior colleague, notice the screen. The project manager, now facing away from the screen to speak, is unaware of what is happening on the screen as he proposes a time for the clash detection exercise: 'So whether that's next week or week commencing $20^{\text {th }}$ June, we can get something set up', he then adds an action to his meeting notes to that effect, while confidently affirming the objective of this workshop: 'That's good, that sounds like a winner. And at least then we can say at the end of the exercise, we've trialled a new bit of software and we've run a clash'.

During this exchange, the timber frame supplier and the BuildCo BIM manager watch as the architect, now focusing intently on her laptop, switches to a $2 \mathrm{D}$ view of the models and then uses a move tool to realign the two models. After making the correction, the architect, appearing nervous as she restlessly touches her earring, looks hesitantly toward the BuildCo BIM manager who continues to discuss the planned clash detection exercise. After noting down details for the planned clash workshop, the project manager asks the architect for an update against planned actions. As the architect displays some of the roofing designs, the project manager faces the architect 
and asks, 'And this now ties up with the model from [the roof truss supplier]?'. The architect averts her eyes back to laptop, closes Revit, and hesitantly scans folder icons on her Windows desktop with the cursor, appearing to look for evidence to support her reply. She then suddenly opens Revit again, and tentatively replies 'But yes, they're, they're doing tiling, um, pretty much, there's a couple of little bits, but, umm, they're dropping in in the right place'. After this qualified confirmation, the project manager asks, 'So, you've already done that clash review?'. As the architect equivocates 'not formally', the BIM manager then suggests to her 'you've done clash avoidance' as the project manager holds his pen hovering over his notes waiting for her confirmation: 'Yes, so far, all the trusses work ... It should work'.

\section{Discussion}

The purpose of this discussion is to explore our three research questions: (i) how do anaesthetic and aesthetic atmospheres enable actors to respectively make sense to learn and learn to make sense; (ii) how are such atmospheres held in tension to enable learning and (iii) how do human representational and purposeful sensemaking and learning practices condition these atmospheres, and how are they in return conditioned by them? After exploring these questions, we will conclude by summarizing the implications of atmospheric analysis for studies of affect, sensemaking and learning.

Before directly answering our first question, it is crucial to first examine how our case supports the notion that learning is composed across two dimensions of sensemaking (Clegg et al. 2005; Colville et al. 2016). Most of the meetings we observed at BuildCo were pervaded by a single form of sensemaking wherein instrumental and conceptual practices reduced ambiguous and 
equivocal events into completed, or soon to be completed, actions ('the project manager rhythmically reads actions from the previous meeting ... physically ticking them off their actions'). We have already characterized this reductive mode of sensemaking as making sense to learn (Colville et al. 2016). This mode of sensemaking is crucial to learning as it allows extant knowledge to be purposefully exploited, and evaluated, within the flow of experience; but, with Clegg et al. (2005) and Colville et al. (2016), we suggest it is not sufficient for learning, as it fails to allow actors to register, let alone organise, ambiguous and equivocal events by learning to make sense differently. This second, more transformative sensemaking dimension is most strongly evident in the tense exchange in the clash detection workshop where one participant challenges the project manager's instrumental understanding of the purpose of the meeting and project with a more exploratory logic ('I think what we were trying to do, the purpose of today was, primarily, to understand what Glue can do'). As Clegg et al. (2005) suggest, such learning to make sense differently is disorganising - even disorganising existing boundaries between 'what is and is not considered learning' (p.157). Summarizing, we can start to see here how learning occurs across two dimensions of sensemaking whereby existing ways of making sense, including of learning, are dis/organised. The crucial concern for atmospheric analysis now becomes to develop a more granular analysis of how atmospheres quasi-autonomously condition the bodily affects, and interactions, that sustain these two dimensions of sensemaking, enabling learning.

Exploring the quasi-autonomous presence and causality of atmospheres means attending to the 'global', or prevailing, affects they generate (Anderson and Ash, 2015: 44). Throughout our case, the global affect we were frequently attuned was confidence: 'a 'joy born of the idea of a future or past thing concerning which the cause of doubting has been removed' (Spinoza, 1996/1977:106). In Deleuzian readings of affect, confidence is figured as a joy corresponding to a passage when bodies encounter each other and increase their potentials for action (Deleuze, 
1988; 1992). Confidence supports anaesthetic atmospheres, and sensemaking practices of making sense to learn by reducing the equivocality and ambiguity of future events (Colville et al. 2016). Confidence imbues this anaesthetic affect in a disjunctive manner. On the one hand, confidence increases the capacities of bodies to affect other bodies - such that the past and future can be known with certainty and future events purposefully shaped as intended. Yet, on the other hand, confidence necessarily reduces capacities for bodies to be affected by, and indeed sense, new, unpredictable events.

The fifth meeting contained several bodily encounters that enacted such passages to confidence, including: the rhythmic completion of action points from the previous meeting; the projection of progress into the future ('we're all pretty much there apart from today's discussions on finishing it'); and humorous injects that displaced boredom (and other transformative affects) (Anderson, 2014). Across all these encounters' bodily capacities to affect other bodies (i.e. to design the models as planned) were augmented, while bodily capacities to be affected by new, unforeseen, events were decreased. The most striking example of such a passage to confidence occurred when the project manager expunged doubt from the architect in her design modelling after her cosmetic workaround. This exchange culminated in the project manager reimagining an open-ended, uncertain future ('clash detection') as predictable and without doubt ('clash avoidance'). Our argument here is not to contest the technical veracity of whether clashes between building components can be confidently predicted prior to being installed, or to analyse the subjective emotions of the individuals involved, but rather, with Deleuze $(1988 ; 1992 ; 2017)$, we suggest such a collective passage away from a state of fear, or doubt, is confidence: understood as an increase in the capacities of bodies to affect other bodies (in our case the design to be delivered without clashes), while a necessary reduction in the capacities of bodies to be affected by doubt in that future. 
Such confident encounters between bodies helped generate a global affect of confidence that then became quasi-autonomous of those bodies. That is, this confidence also quasiautonomously enveloped bodies in the meetings even when bodily passages were far from confident. The disconnection between the production and function of confidence is evident even before the fifth meeting's clash detection workshop, as occurred during the fourth meeting when several participants silently watched the architect detect a misalignment in the design models, and then frantically search for and employ a cosmetic fix. As the participants observed a fearful affect (i.e. an increasing in doubt as to how the future will unfold) emerge in the encounter between the architect, the design model and her laptop, they already appeared anesthetized to doubt, not just by the confident talk of the project manager ('That's good, that sounds like a winner') but by an instilled, and rehearsed, global capacity to be affected by confidence. Their bodies, including the architect's, were already angled to confidently make sense to learn and reduce equivocality and ambiguity in the design models. Disorganising potentials of learning to make sense differently, such as intensifying doubt to challenge the instrumental narrative of learning as confident progress, remained forestalled or were marginalized. This marginalization of affects, except confidence, is further apparent in the knowing smile of the architect towards the steel frame supplier in the fifth meeting, out of sight of the project manager, when that supplier is asked to report on his progress. Such examples do not only evidence the marginalization of such transformative aesthetic affects, but also the quasi-autonomous presence of what we conceptualize as a confident atmosphere over specific bodily encounters. Our analysis thus challenges the existing literature of affect, sensemaking and learning where the diminishment of learning is associated with intense individual emotions (Catino and Patriotta, 2013; Heaphy, 2017; Ucbasaran et al. 2013). The confidence we were attuned was far from intense, or hubristic, rather it was because it was atmospherically 
assembled, and thus diffusive and lingering, that it anaesthetized sensemaking and forestalled learning.

Thus far we have explored the emergence of a specific atmospheres that conditioned a particular dimension of sensemaking that we have termed making sense to learn; however, as Clegg et al. (2005: 155-6) explain, learning does not occur within a single practice of sensemaking or even between absolute alternations between dis/organising sensemaking processes but across more entangled tensions, transformations and oscillations. Thus, we now turn to our second question and explore how the lingering, and diffusive, presence of this anaesthetizing confident atmosphere, amid the aesthetic atmosphere of shock and surprise of the misaligned model in the clash detection workshop, conditioned learning. Put differently, our analysis is now concerned with understanding the conditions that allowed the interplay of aesthetic and anaesthetic atmospheres in the clash detection workshop to disorganise prior sensemaking and thus render learning possible.

The capacities for such atmospheric transformations to be conditioned can be empirically elaborated by returning to the episode in the fifth meeting when the architect instilled her cosmetic workaround to align the design models. During this episode, a confident atmosphere diminished the capacity for her cosmetic workaround to intensify fear among the participants and overcome the threshold for confidence to orientate the meeting. Viewed as such, this encounter appears to merely constitute another passage to confidence. Yet, this passage was also important in generating a new material threshold for confidence: the visible alignment of the design model in BIM became a limit under which sensemaking and learning in the project was confidently rendered meaningful as an instrumental and conceptual practice of making sense to learn ('that's good, that sounds like a winner. And at least then we can say at the end of the exercise, we've trialled a new bit of software and we've run a clash'). Here we can 
register how an atmosphere of confidence generated the conditions, or threshold, for its own transformation. Thus, in the subsequent clash detection workshop, the sudden, highly visible, appearance of the misaligned model transformed this confident atmosphere, decreasing the confident capacities of human bodies to act with doubt ('Well, we can't finalise the models because the models don't even line up today!), while joyfully increasing their openness to the new ('Glue is showing the problem. There is a coordinate problem') and generating an atmosphere of surprise and shock. Put more formally, the conditions for reductive practices of making sense to learn were supplemented with conditions for exploratory practices of learning to make sense differently ("I think what we were trying to do, the purpose of today was, primarily, to understand what Glue can do'). Although some studies have suggested certain specific atmospheres can enable learning, such as care (Robinson, 2017: 278) or even confidence (Morris, 2018: 52), our analysis indicates that neither aesthetic or anaesthetic atmospheres enable learning rather it is the co-existence, interaction, and transformation of atmospheres that conditions learning. Indeed, it was only during the collapse of the global affect of confidence among the participants in the meeting occurred, that the participants learned to make sense differently of how they had previously been making sense to learn and could then make sense to learn again by reducing ambiguity and equivocality in events by correcting the datums in their design models. This entangled collision between orderingdisordering-ordering constitutes learning (Clegg et al. 2005).

We can now turn to our final question and explore the interplay between human representational and purposeful sensemaking and learning practices and atmospheres. Throughout our analysis we have suggested how often highly purposeful meeting talk and other actions enacted specific affects, notably confidence and doubt, that enveloped bodies and modulated their potentials to act. Thus, our analysis recognizes that although the generation of atmospheres, whether relaxed confidence or nullifying shock, certainly involves interactions 
with material bodies (e.g. BIM technologies, facial expressions, desks, projectors, ceiling lights), its patterning is also shaped by representational and purposeful bodies and practices (e.g. confident meeting talk, scripted meeting agendas and visual designs). In order to more fully explore these textual and purposeful dynamics, it is useful to reflect on how confidence was sustained. Throughout the design project, the participants, especially the project manager, verbally anticipated confidence, not doubt, in past and future events ('we're all pretty much there', 'And this now ties up with the model', 'That's good, that sounds like a winner'). With Deleuze $(1988 ; 1992)$ we argue that these verbal passages that discursively expect confidence (cf. Edensor, 2012) do not symbolically represent confidence, they are confidence - a joyful, and disjunctive, increase in capacities to affect future events and (not be) affected by future events. As Deleuze (2017: 17) explains of human bodies, non-representational modulations in 'the individual's capacity to act or engage with other agents (human or non-human)' (Gherardi, 2017: 348) are always generated by flows in representational ideas that include talk and meaning (see Sage et al. 2019).

We propose that the promulgation of confident atmospheres is especially vital in conditioning sensemaking as a purposeful activity of making sense to learn by reducing equivocality and ambiguity in events, thus enabling instrumental action. This is because fixed outcomes, and (autonomous) human potentials for action, can only be assumed as such through the dampening of doubt in their potential existence. However, despite these instrumental affects, confidence cannot be readily willed into existence by human intent because it is always already partly conditioned, like all affective atmospheres, through non-human bodily capacities (Anderson, 2014; Julmi, 2017). The de-centred production of confidence is evident in the moment after the architect hesitantly searches for proof of model alignment on her laptop; her nervousness, and her hesitant confirmation that the model is aligned ('there's a couple of little bits, but, umm, they're dropping in in the right place') enacts doubt in a manner that could threaten the 
anticipated atmosphere of confidence and thus sensemaking and learning as instrumental and conceptual. However, as she speaks doubt, the project manager hovers his pen directly over the meeting agenda awaiting confirmation of model alignment - thus, he physically, not verbally, anticipates her confidence. At this point, the capacity of the project manager's hand, pen and the meeting agenda, along with the confirmatory statement of the BIM manager ('you've done clash avoidance'), and imaginings of past and future events, all combine to help condition an atmosphere of confidence that constrains her doubt ('Yes, so far, all the trusses work ... It should work'). In this instance confidence is not willed into existence by the project manager, rather it emerges through the relations between bodies, some material, some discursive, some human, some not, some present, some not, as an expectation to be confident. Yet, confidence does at least appear strongly conditional on the instrumental expectation that it will emerge as an atmosphere in this setting (Edensor, 2012). Thus, our analysis also challenges the notion that affects should be figured as an extra-discursive, extra-cognitive, excess, separate to representational and purposeful sensemaking and learning practices (cf. Introna, 2018; Gherardi, 2017).

\section{Conclusion}

The most wide-ranging implication of our analysis is that capacities for learning are constituted within and through transformations between anaesthetic and aesthetic atmospheres. Our specific case focuses on the transformation from anaesthetic to aesthetic atmospheres. Further atmospheric analyses of sensemaking and learning might also explore aesthetic to anaesthetic transformations, or even those concerning specific an/aesthetic to an/aesthetic atmospheres. Organisational scholarship has long argued that learning consists of entangled tensions, 
transformations and oscillations between ordering (exploitative) and disordering (exploratory) practices (Clegg et al. 2005; March, 1991) and that these opposing practices correspond with respective ordering/disordering dimensions of sensemaking (Colville et al. 2016; Izak, 2015; Weick and Westley, 1999). To this end, recent empirical studies have proposed more or less purposeful strategies to order/disorder sensemaking, thus enabling learning (e.g. Calvard, 2016; Guiette and Vandembempt, 2016; Izak, 2015). Despite such insights, less is understood about the (affective) conditions that render these different dimensions of sensemaking, and thus learning, possible. We propose atmospheric analyses of sensemaking and learning to help understand these conditions.

Atmospheric analysis suggests that the transformation of atmospheres and their global affects, such as confidence, constitutes a vital condition for organising/disorganising sensemaking enabling learning. The Deleuzian concept of thresholds through which bodies can modulate together to affect and be affected (Deleuze, 1988; 1992) is especially useful in theorizing these processes. Atmospheric affective thresholds are understood as the limits through which atmospheres, and their global affects, such as confidence, can be sustained or transformed. These atmospheres, and their thresholds, have also been shown here to be partly amenable to purposeful assembly within even the most mundane episodes in organisational life, such as meetings. To be clear, we do not want to suggest that atmospheres can be willed into existence, but certain bodies, and their affects, like meeting agendas, progress plans, cosmetic workarounds, expectant gazes and confident talk, can and often are assembled together to help condition the production and maintenance of specific atmospheres (cf. Degen et al. 2017; Edensor, 2012; Morris, 2018), constraining and enabling learning. Crucially, these processes of atmospheric assembly have also been shown to generate unintended atmospheric consequences where, for example, the initial displacement of learning can imbue conditions for its re-emergence. Indeed, our analysis suggest that it can be during the most purposeful acts 
of sustaining an atmosphere to anaesthetize bodies from sense and learning, that new capacities for learning to make sense differently emerge, enabling learning. Future studies might broaden analyses of such complex atmospheric transformations to also consider how specific atmospheres might be purposefully transformed externally through the collision of multiple atmospheres. Such studies might build upon a handful of organisational studies already considering a range of other atmospheric affects, including loss (Bell and Vachhani, 2019), excitement (Michels and Steyaert, 2017), and enchantment (Gherardi, 2017), as well as those considering the more purposeful design of specific atmospheres within learning places (Morris, 2018; Robinson, 2017). Above all, what is required are studies that not only help scholars make conceptual sense of specific atmospheres of learning but also help researchers, and reflective practitioners, learn to make sense differently of how atmospheres transform and are transformed - to enable sense - to enable learning.

\section{References}

Anderson B (2009) Affective atmospheres, Emotion, Space and Society, 2, 77-81.

Anderson B (2014) Encountering affect: capacities, apparatuses, conditions, Ashgate: Farnham.

Anderson B and Ash J (2015) Atmospheric Methods. In: Vannini, P. (Ed) Non Representational Methodologies: Re-Envisioning Research. London, UK: Routledge Publishing, pp.34-51.

Bell E and Vachhani S (2019) Relational Encounters and Vital 
Materiality in the Practice of Craft Work, Organization Studies, Available at: DOI: $10.1177 / 0170840619866482$.

Brown A (2000) Contemplating the emotional component of learning: the emotions and feeling involved when taking an MBA, Management Learning, 31(3): 275-293.

Calvard T (2016) Big data, organizational learning, and sensemaking: Theorizing interpretive challenges under conditions of dynamic complexity, Management Learning, 47(1): $65-82$.

Catino M and Patriotta G (2013) Learning from Errors: Cognition, Emotions and Safety Culture in the Italian Air Force, Organization Studies, 34(4): 437-467.

Colville I, Pye A and Brown A (2016) Sensemaking processes and

Weickarious learning, Management Learning, 47(1): 3-13.

Cornelissen J, Mantere S and Vaara E (2014) The Contraction of Meaning: The Combined Effect of Communication, Emotions, and Materiality on Sensemaking in the Stockwell Shooting, Journal of Management Studies, 51(5): 699-736.

Creed D, Hudson B, Okhuysen G and Smith-Crowe K (2014) Swimming In A Sea Of Shame: Incorporating Emotion Into Explanations Of Institutional Reproduction And Change, Academy Of Management Review, 39(3): 275-301.

Cunliffe A and Coupland C (2012) From hero to villain to hero: Making experience sensible through embodied narrative sensemaking, Human Relations, 65(1): 63-88. 
Clegg S, Kornberger M and Rhodes C (2005) Learning/becoming/organising, Organization, $12(2), 147-167$.

Degen M, Melhuish C and Rose G (2017) Producing place atmospheres digitally: Architecture, digital visualisation practices and the experience economy, Journal of Consumer Culture, 17(1): 3-24

Deleuze G (1988) Spinoza: Practical Philosophy, City Lights Books: San Francisco.

Edensor T (2012) Illuminated atmospheres: anticipating and reproducing the flow of affective experience in Blackpool, Environment and Planning D: Society and Space, 30: 11031122.

Fineman, S. (1997) Emotion and management learning, Management Learning, 28(1): 13-25.

George J and Jones G (2001) Towards a process-model of individual change in organizations, Human Relations, 54(4): 419-444.

Gherardi S (2016) To start practice theorizing anew: The contribution of the concepts of agencement and formativeness, Organization, 23(5): 680-698.

Gherardi S (2017) One turn ... and now another one: Do the turn to practice and the turn to affect have something in common?, Management Learning, 48(3) 345-358.

Gherardi S (2018) Theorizing affective ethnography for organization studies, Organization, 1-20, Available at: https://doi.org/10.1177/1350508418805285. 
Guiette A and Vandenbempt K (2016) Learning in times of dynamic complexity through balancing phenomenal qualities of sensemaking, Management Learning, 47(1): 8399.

Heaphy E. (2017) Dancing On Hot Coals": How Emotion Work Facilitates Collective Sensemaking, Academy of Management Journal, 60(2): 642-670.

Introna L (2018) On the Making of Sense in Sensemaking: Decentred Sensemaking in the Meshwork of Life, Organization Studies, 1-20, Available at: https://journals.sagepub.com/doi/10.1177/0170840618765579

Izak M (2015) Learning from a fool: Searching for the 'unmanaged' context for radical learning, Management Learning, 46(1): 87-104.

Julmi J (2017) The Concept of Atmosphere in Management and Organization Studies, Organizational Aesthetics, 6(1): 4-30. Available at: https://digitalcommons.wpi.edu/oa/vol6/iss1/2 (accessed 11th March 2019)

Lancione M (2017) Revitalising the uncanny: Challenging inertia in the struggle against forced evictions, Environment and Planning D: Society and Space, 35(6): 1012-1032.

Latour B (2005) Reassembling the social: an introduction to actor-network theory, Oxford University Press: Oxford.

Maitlis S and Christianson M (2014) Sensemaking in Organizations: Taking Stock and Moving Forward, Academy of Management Annals, 8(1): 57-125, http://dx.doi.org/10.1080/19416520.2014.873177. 
MacLure M (2013a) 'Classification or Wonder? Coding as an Analytic Practice in Qualitative Research', In: Coleman, R. and Ringrose, J. (eds) Deleuze and Research Methodologies, Edinburgh: Edinburgh University Press. pp. 164-83.

MacLure M (2013b) Researching without representation? Language and materiality in postqualitative methodology, International Journal of Qualitative Studies in Education, 26(6): 658-667.

March J (1991) Exploration and exploitation in organizational learning, Organization Science 2(1): 71-87.

Massumi B (2015) Politics of Affect, Polity: Cambridge.

Michels C (2015) Researching affective atmospheres, Geographica Helvetica, 70: 255-263.

Michels C and Steyaert C (2017) By accident and by design: Composing affective atmospheres in an urban art intervention, Organization, 24(1): 79- 104.

Morris, J. (2018) Decentring ingenuity: Calculation, intuition and atmospheres in the Bank of England's financial literacy assemblages, Geoforum, 90: 45-54.

Ringrose J and Renold E (2014) " $\mathrm{F}^{* *} \mathrm{k}$ Rape!”: Exploring Affective Intensities in a Feminist Research Assemblage, Qualitative Inquiry, 20(6): 772- 780.

Robinson,P (2017) Learning spaces in the countryside: university students and the Harper assemblage, Area, 50(2): 274-282. 
Sandberg, J. and Tsoukas, H. (2015) Making sense of the sensemaking perspective: Its constituents, limitations, and opportunities for further development, Journal of Organizational Behavior, 36, S6-S32.

Sage D, Vitry C and Dainty A (2019) Exploring the Organisational Proliferation of New Technologies: An Affective Actor-Network Theory, Organization Studies, 1-19, Available at: https://journals.sagepub.com/doi/10.1177/0170840618815524

Spinoza B (1996). Ethics (trans. Curely, E) London: Penguin.

Steigenberger N (2015) Emotions in sensemaking: a change management perspective, Journal of Organisational Change Management, 28 (3): 432-451.

Stewart K (2011) Atmospheric attunement, Environment and Planning D: Society and Space, 29: 445-453.

Ucbasaran D, Shephard D, Lockett A and Lyon J (2013) Life After Business Failure: The Process and Consequences of Business Failure for Entrepreneurs, Journal of Management, 39(1): 163-202.

Vince R (2011) The Spatial Psychodynamics of Management Learning, Management Learning, 42(3): 333-347.

Weick K (1990) Introduction: cartographic myths in organisations. In: Huff, A. (Ed) mapping strategic thought, John Wiley and Sons: London, pp. 1-10.

Weick K (1995) Sensemaking in organizations, Sage: London. 
Weick K (2010) Reflections on enacted sensemaking in the Bhopal disaster, Journal of Management Studies, 47(3): 530-557.

Weick K and Westley F (1999) Organizational learning: Affirming an oxymoron. In: Clegg S, Hardy, C and Nord, W. (eds) Managing Organizations: Current Issues. London: SAGE, pp. 190-208.

Weick K, Sutcliffe K and Obstfeld D (2005) Organizing and the process of sensemaking, Organization Science, 16(4): 409-421. 